\title{
A Colorimetric Paper Sensor for Lactate Assay Using a Cellulose-Binding Recombinant Enzyme
}

\author{
Guoying Dai ${ }^{\mathrm{a}, \mathrm{b}}$, Jinglin $\mathrm{Hu}^{\mathrm{b}}$, Xueyan Zhao ${ }^{\mathrm{c}}$, Ping Wang ${ }^{\mathrm{a}, \mathrm{b}, *}$
}

${ }^{a}$ State Key Laboratory of Bioreactor Engineering, Biomedical Nanotechnology Center, East China University of Science and Technology, Shanghai 200237, P. R. China

${ }^{\mathrm{b}}$ Department of Bioproducts and Biosystems Engineering, University of Minnesota, Minnesota 55108, United States

${ }^{c}$ Department of Chemical Engineering, California Baptist University, Riverside, CA 92504, United States

*Corresponding Author: ping@umn.edu 


\begin{abstract}
A new fabrication technology for effective preparation of paper-based biosensors using affinity-binding enzymes is developed. Lactate dehydrogenase (LDH) fused with a cellulose binding domain (CBD) is produced to allow one-step purification and immobilization of the enzyme on paper. Results demonstrate that the binding capacity of the recombinant enzyme is as high as $22 \mathrm{mg}$-enzyme/g-paper, with much improved stability (by a factor of 25-fold) in comparison to the native parent enzyme. That ensures the solid phase bioassay reactions on surface of the paper sensor are not subject to limitations of enzyme availability, and affords much extended sensor shelf life at the same time. The paper sensor shows a linear detection range of $0.5 \sim 8 \mathrm{mM}$ of lactate, with changes in color intensity detectable within a much broader concentration range examined (up to $16 \mathrm{mM}$ ). The colorimetric display is suited for readouts using either human eyes or hand-held imaging devices such as smart phones. This work promises of a new strategy of developing high performance paper-based sensors for point-of-care diagnosis applications.
\end{abstract}

Key words: paper-based biosensor; cellulose binding domain; lactate; lactate dehydrogenase; enzyme; biocatalysis 


\section{Introduction}

Paper-based sensors offer simple, affordable, portable, and disposable analytical devices appealing for many applications including clinical diagnosis, food quality control, and environmental monitoring [1-4]. To make it suited for point-of-care applications, detection with paper sensors is mostly achieved via colorimetric readouts, although electrochemical [1] or electrochemiluminescent [5] signals have also been examined for paper sensors. Colorimetric detection offers the convenience for analysis with naked human eyes, or hand-held devices such as smart phones and photo scanners, with computerized analyses and calculations readily available without much software and hardware requirements [2, 6-9].

One key challenge in preparing enzyme-based paper biosensors is the application and binding of enzymes onto paper substrates. Enzymes may be immobilized on paper through different strategies. Among the different enzyme immobilization techniques applied, enzyme adsorption is the most popular approach since only simple operation steps are required [10]; however, simple adsorption is not necessary effective since it promises only weak binding forces and low binding capacities of the enzymes [11]. The adsorbed enzymes are also largely vulnerable to harsh external conditions, leading to concerns on sensor reliability. Other methods such as chemical cross-linking [12], thin film entrapment [13], and microencapsulation (capsules deposited or mixed with the pulp) [14] could improve the efficiency of enzyme immobilization. However, those are 
generally achieved mostly in a manner with very limited accessibility of the enzymes for assay reactions, and generally with big compromises in the complexity and cost of sensor preparation.

The current work examines a new strategy for preparing paper sensors with simple yet efficient procedures. Toward that, recombinant enzymes that are fused with a cellulose-binding domain (CBD) appear to be particularly promising. CBD in nature affords carbohydrate binding functionality for cellulases [15]. Previous researches have demonstrated the use of various kinds of CBD fused with target enzymes to realize efficient enzyme production and purification [16-18]. CBD-recombinant enzymes may serve the purpose for enzyme-based paper sensors with several advantages, including high binding capacity and improved stability that are eventually translated into the performance of biosensors. It offers convenient and simple preparation by immobilizing the enzyme onto paper substrates via highly specific affinity binding, eliminating the use of any other supporting materials and chemicals while improving the overall efficiency of enzyme immobilization, leading to more affordable and reliable biosensors at the same time. 


\section{Experimental}

\subsection{Materials}

Lactate, $\beta$-Nicotinamide adenine dinucleotide $\left(\mathrm{NAD}^{+}\right)$, 1-methoxy phenazine methosulfate (PMS), $\mathrm{MnCl}_{2} \cdot 4 \mathrm{H} 2 \mathrm{O}, \mathrm{FBP}, \mathrm{DTT}, \mathrm{NaCl}$, glycerol, Tris base and Hydrochloric acid were purchased from Sigma Aldrich (Milwaukee, USA). Filter paper $\left(\right.$ Whatman $^{\circledR}$ ) was purchased from Sigma Aldrich (Milwaukee, USA). Etrazolium salt (WST-8) was purchased from Santa Cruz Biotechnology (Paso Robles, CA, USA). The WST-8 assay solution used in this paper is the mixture of $10 \mathrm{mM}$ WST-8 and 0.2 PMS in $50 \mathrm{mM}$ Tris-HCl. Lactate dehydrogenase (LDH) and cellulose binding domain (CBD) were cloned from Lactobacillus casei ATCC 334 and Clostridium Thermocellum DSMZ 2360, respectively. Escherichia coli, DH5 $\alpha$ from (Invitrogen, China) was used as the host cell for all DNA manipulations. The E. coli BL21 (DE3) (Invitrogen, China) was used for recombinant protein expressions.

\subsection{Plasmid construction and LDH overexpression}

Molecular cloning was carried out following a typical molecular cloning protocol. Specifically, the encoding sequences for enzymes LDH-CBD were cloned via PCR using the genomic DNA of Lactobacillus casei ATCC 334 and Thermocellum DSMZ 2360 as templates. Overlap extension PCR was used to construct the fusion genes for CBD-LDH. The gene specific primers were shown in Table 1. E. coli BL21 with plasmid pET28aCBD-LDH were cultured in LB medium with $50 \mu \mathrm{g} / \mathrm{mL}$ kanamycin at $200 \mathrm{rpm}$ and $37 \circ \mathrm{C}$. Protein expression was induced with $200 \mu \mathrm{M}$ IPTG when OD at $600 \mathrm{~nm}$ reached 0.6 0.8. The cell pellets were harvested after an overnight of overexpression at $30^{\circ} \mathrm{C}$. To obtain the cell lysate for the following filter paper bindings, the cell pellet from $125 \mathrm{~mL}$ culture 
was ultrasonificated in $25 \mathrm{~mL} 50 \mathrm{mM}$ Tris- $\mathrm{HCl}$ buffer at $\mathrm{pH} 8.5$ containing $10 \%$ glycerol and $300 \mathrm{mM} \mathrm{NaCl}$.

\subsection{Protein adsorption on paper}

Whatman® filter paper was punctured to produce round-shaped paper flakes of 6 $\mathrm{mm}$ in diameter. Binding of proteins on paper flakes was conducted in a $50 \mathrm{mM}$ Tris- $\mathrm{HCl}$ buffer $(\mathrm{pH} 8.5)$ at $30^{\circ} \mathrm{C}$. After adsorption reached equilibrium (>30 min), the paper specimen was retrieved via centrifugation, a fresh Tris- $\mathrm{HCl}$ buffer $(50 \mathrm{mM}, \mathrm{pH} 8.5)$ was used to wash non-specifically bound proteins from the paper. The protein content in the immobilization and washing solutions was detected using Bradford method with bovine serum albumin as the protein standard, and the amount of protein missing from the originally added was then calculated and taken as the quantify the protein bound onto the paper.

\subsection{Paper sensor reaction procedure}

For lactate detection, $5 \mu \mathrm{L}$ of detection agent solution (containing $3 \mathrm{mM} \mathrm{FBP}, 10$ $\mathrm{mM} \mathrm{NAD}^{+}$and $6 \mathrm{mM} \mathrm{Mn}^{2+}$ ) was first added onto the paper sensor. After incubated for 10 min, $7 \mu \mathrm{L}$ of a sample solution containing lactate and WST-8 (v/v, 1:1) was added onto the working zone of the paper sensor. The paper sensor was placed under a plastic lid to

allow assay reaction continue for $15 \mathrm{~min}$, the assay reaction was then stopped by leaving the sensor to open air for another $15 \mathrm{~min}$ to evaporate the moisture. Finally, color intensity of the image was captured by using a computerized scanner and analyzed using an imaging software (Image-J).

\subsection{Stability and activity assay}


To study the stability of paper sensor, the LDH-CBD binding paper were sealed in airtight plastic bags and stored at $4^{\circ} \mathrm{C}$, room temperature and $50^{\circ} \mathrm{C}$ for up to 3 weeks. Assays using the conditioned paper sensors were carried out with the standard procedure as mentioned above.

Enzyme activities (free LDH, free and immobilized CBD-LDH) were measured by detecting the increase in the concentration of NADH, as indicated by absorbance at 340 $\mathrm{nm}\left(\varepsilon \mathrm{NADH}, 6,220 \mathrm{M}^{-1} \mathrm{~cm}^{-1}\right)$, by using a DU $800 \mathrm{UV}$-vis spectrophotometer (Beckman Coulter, USA). Reaction conditions were set as $30^{\circ} \mathrm{C}$ in $50 \mathrm{mM}$ Tris- $\mathrm{HCl}$ buffer at $\mathrm{pH} 8.5$ containing $10 \mathrm{mM} \mathrm{NAD}+3 \mathrm{mM} \mathrm{FBP}$ and $6 \mathrm{mM} \mathrm{MnCl}_{2}, 50 \mathrm{mM}$ lactate $[19,20]$. One activity unit was defined as the amount of enzyme that produces $1 \mu$ mol NADH per minute.

\section{Results and discussion}

\subsection{Fusion of $L D H$ with $C B D$}

Both lactate oxidase (LOD) and dehydrogenase (LDH) have been applied for analysis of lactate of biological specimens [21]. Nevertheless, LDH is less popular for lactate sensors despite its high reactivity, stability and selectivity, most probably due to its requirement of cofactors (especially NADH). For colorimetric analyses of lactate, hydrogen peroxide, which is derived as a byproduct from the LOD-facilitated oxidation 
reaction, has been used commonly as an indicator for detection of the reaction rate, which is eventually correlated to the content of lactate of the samples [22]. Since the reaction rate is generally sensitive to various operational factors, restrict control of reaction conditions is generally required. For a paper sensor suited for point-of-care assays that involve reactions constrained within a thin film coating phase, indicator is required to have good stability, and should measure the gross amount of the analyte under variable environmental conditions, thereby providing more consistent assays. Accordingly, the cofactor, which is stable and less toxic to the enzyme, as required for the LDH-catalyzed oxidation of lactate, is selected as an indicator for the paper sensor in the current work.

LDH fused with CBD was then designed for the paper sensor. In order to provide enough flexibility to allow high binding affinity, the widely used (G4S)3-linker was placed between the LDH and CBD. This linker, composed of glycines (G) and serines (S) with maximum hydrophilicity, is known to have a high flexibility [23], which is beneficial to maintain the freedom necessary for the protein moieties to be fully functioning [24]. With the primers as listed in Table 1, LDH and CBD along with the (G4S)3-linker were first amplified separately by using Lactobacillus casei ATCC 334 and Clostridium Thermocellum DSMZ 2360, respectively. The recombinant plasmid expressing the CBD-LDH recombinant protein was constructed subsequently through overlap extension PCR, followed by protein expression and purification. SDS-PAGE assay showed that the recovered CBD-LDH has a molecular weight of $54 \mathrm{kDa}$ (native LDH has a Mw of $35 \mathrm{kDa}$, which was expressed as a control through the same procedure) (Fig. 1). The overall expression level appeared to be high, with the overall yield of CBDLDH was around $12.5 \mathrm{mg}$ pure/1 g pellet (wet) from $125 \mathrm{~mL}$ culture cells. Interestingly, 
activity assays showed that $\mathrm{LDH}\left(0.28 \times 10^{6} \mathrm{U} / \mathrm{mmol}\right)$ and CBD-LDH $\left(0.23 \times 10^{6} \mathrm{U} / \mathrm{mmol}\right)$ have approximately the same specific activity at $\mathrm{pH} 8.5$, despite the changes in molecular weight. This could be attributed to the flexibility of the (G4S)3 linker between LDH and CBD.

\subsection{Binding of LDH-CBD on cellulosic paper}

The binding capacity of CBD-LDH was evaluated via adsorption tests. Samples tested included crude CBD-LDH from cell lysate supernatant, His-Tag column purified CBD-LDH and purified native LDH. Fig. 2 shows the adsorption curves. It appeared that filter paper could absorb a large amount of CBD-LDH, while the adsorption of native LDH was hardly detectable, indicating that the functionality of CBD moiety of the recombinant protein retained very well. Among the samples tested, purified CBD-LDH exhibited the highest binding capacity (Table 2). The binding of CBD-LDH from the crude was lower, indicating interference of other impurities, but was still significantly higher than native LDH. The maximum binding capacities of CBD-LDH was found to be about $0.40 \mu \mathrm{mol} / \mathrm{g}$-paper, while that of native LDH was $0.006 \mu \mathrm{mol} / \mathrm{g}$-paper (Table 2). Using a similar recombinant protein strategy, Hong and colleagues have shown that the maximum protein adsorption capacity of thioredoxin-GFP-CBD (62 kDa, monomer) was as high as $1.39 \pm 0.045 \mu \mathrm{mol} / \mathrm{g}$ of filter paper [25]. That adsorption study was conducted in $50 \mathrm{mM}$ sodium citrate buffer $(\mathrm{pH} 6.0)$ at $50^{\circ} \mathrm{C}$, which is the preferred reaction condition of cellulose hydrolysis catalyzed by cellulase [25]. In current work, in order to maintain the activity of $\mathrm{LDH}$, we tested the binding capacity at $30^{\circ} \mathrm{C}$ and $\mathrm{pH}$ at 8.5 , best for the enzyme activity instead of optimized binding conditions. Activity tests also 
showed the paper-bound recombinant enzyme maintained the activity of LDH, with an apparent activity determined as $0.02 \times 10^{6} \mathrm{U} / \mathrm{mmol}$-enzyme, $\sim 10 \%$ of the activity of the enzyme in solution. The lower apparent activity of the paper-bound LDH is mostly a reflection of mass transfer limitations instead of enzyme inactivation, as has been observed for most immobilized enzymes.

For the purpose of comparison, we also developed a CBD-fused enhanced green fluorescent protein (EGFP), which showed a binding capacity of $\sim 0.45 \mu \mathrm{mol} / \mathrm{g}$-paper, very close to that of CBD-LDH under the same conditions (Table 2). The slight difference in binding capacities is probably due to the difference in molecular sizes ( $\mathrm{Mw}$ of EGFP is $29 \mathrm{kDa}$, smaller than LDH). CBD-EGFP immobilize on paper was further analyzed by using laser scanning confocal microscopy (Fig. 3). As shown in Fig. 3B, the recombinant protein distributed well throughout the porous fibrous network of the filter paper. That is one property desired for development of paper sensors. Previous work showed that uneven distribution of reagents on paper could hamper sensor sensitivity, accuracy and repeatability [26, 27].

\section{3 Lactate assay with LDH paper sensor}

The preparation of paper sensor is achieved by binding CBD-LDH enzyme from crude cell lysate directly onto filter paper, followed by drying at room temperature for about one hour [18] (a scheme demonstrating the process is shown in Fig. 4). The prepared test strips were sealed in a plastic bag and stored at a dry environment before being used. Even though the binding capacities are different between the crude and purified enzymes, our reaction tests showed that the assay reaction conducted with the 
crude enzyme-bound paper sensors could reach completion under the given conditions, and demonstrated essentially the same degree of color development as that achieved with purified enzyme. That observation suggests that, the enzyme loading realized even with the crude enzyme extract is high enough to ensure assays free of enzyme availability limitations.

Color development for the paper sensor is achieved in the current work by using the formazan reaction scheme (Fig. 5). WST-8 is one of the most widely used tools in cell biology for measuring the metabolic activity of cells ranging from mammalian to microbial origins [28]. Bioassay tests were initialized by adding $7 \mu \mathrm{L}$ of mixture solution of substrate and WST-8 onto the paper sensor, which was then placed under one plastic cover to keep the reaction under ambient condition for $15 \mathrm{~min}$. The paper sensor was then open to air for about $15 \mathrm{~min}$ to evaporate the residual moisture before color reading. Color intensity was captured by using a computerized scanner and analyzed with an imaging software (Image-J) where gray value of the image was applied [2]. While the electronic analyses ensure our calibration of the sensor with higher reliabilities, readouts using human eyes could also be adopted with proper color reading scales for future pointof-care assay applications [7, 29].

Considering the $\mathrm{pH}$-sensitive nature of enzymatic reactions, the effect of $\mathrm{pH}$ on the lactate paper sensor was examined over a $\mathrm{pH}$ range of 7.0 to 8.5 for a sample solution of known lactate concentration $(3 \mathrm{mM})$. As shown in Fig. 6, strongest sensor responses were observed when $\mathrm{pH}$ reached 8.0 and 8.5 , which matches the optimum $\mathrm{pH}$ for the enzyme $\mathrm{LDH}$ [30]. Therefore, the $\mathrm{pH}$ was fixed at 8.5 for subsequent tests. 
Color development of the paper sensor corresponded very well to changes in lactate concentration over the concentration range tested (up to $16 \mathrm{mM}$, Fig. 7). To examine the effect of reaction time on color development, the assay reaction time (reaction under the covered condition before being air dried) was also allowed to last $30 \mathrm{~min}$ in one set of the tests instead of the standard 15 min (Fig. 7A). The calibration curves for both reaction times overlapped for lower lactate concentrations, indicating the completion of the reaction was achieved for both cases; however, the linear range for 30-min test was extended to $8 \mathrm{mM}$ from the $5 \mathrm{mM}$ for 15 -min assays, indicating completion of the reaction requires additional time for higher lactate concentrations. Overall, we may conclude here that, the color development is a reflection of the total amount of target analyte (lactate) added from the sample, it should offer very good reliability of the assay; the liner range of the sensor can be extended by extending the time of reaction (via keeping moisture level of the sensor) if needed. It is also noteworthy that color changes corresponded very well to concentration of the samples within the range of the tests (up to $16 \mathrm{mM}$ ), providing the flexibility of the sensor for future applications for different types of samples (like those from food industry). The linear range of $0.5-5 \mathrm{mM}$ achieved with 15-min assay should indeed meet well the needs for most clinical assays already [21], considering the lactate content in blood generally ranges from $0.5-1.5 \mathrm{mM}$ for people at rest [31,32]. The linear range is actually wider than what was previously reported in literature [2,33]. More accurate or broader linear detection range has been reported for electrochemistry and nanotechnology-based biosensors [34, 35]; however, those implicate much more sophisticated preparation and application procedures, not necessary satisfying the simplicity and reliability as required for point-of-care diagnosis. 
Fig. 7B demonstrates the regression correlation of the linear range of the assays. In addition to digital analysis, such degree of variation in color development should also be very evident to human eyes for convenient reading for future applications (Fig. 7C).

\subsection{Sensor performance and stability}

Retaining the biological activity of enzymes under long-term storage is one of the major challenges faced in developing paper-based sensors [36, 37]. In the current work, the lactate sensors were examined for stability of storage at different temperatures. The stability was examined by measuring sensor performance as a function of storage time. As a result, the lactate sensor showed almost no loss of sensitivity over a period of 15 days, both at $4^{\circ} \mathrm{C}$ and room temperature, performing at the same level as freshly prepared paper sensors (Fig. 8A).

However, when tested at a higher temperature $\left(50^{\circ} \mathrm{C}\right)$, the sensor sensitivity lost quickly even for the first few days of incubation (Fig. 8A). It is most likely related to thermal sensitivity of the enzyme LDH [38]. We therefore examined enzyme stability as a function of temperature by using standard enzyme activity assay (Fig. 8B). As a result, it showed that the enzyme had a half lifetime of about 21 days when stored at $4^{\circ} \mathrm{C}$ and room temperature, but dropped sharply to less than a few hours at $50^{\circ} \mathrm{C}$ (Fig. 8B). Due to the high enzyme binding capacity, sensor sensitivity could be maintained even if certain portion of the enzyme loses activity during storage. That is the case for sensors stored at room temperature or $4^{\circ} \mathrm{C}$, for which $100 \%$ sensor performance can be maintained even though enzyme activity got lost by $30 \%$ after 15 days (Fig. 8A, B). However, when larger portion of the enzyme activity get lost, the sensor could not function properly any more. 
That is case when the sensor was exposed to $50^{\circ} \mathrm{C}$.

The sensor stability appeared to be much improved in comparison to results as reported previously [37, 38], which has evidently benefited from the strong binding affinity of CBD moiety of the recombinant enzyme considering surface-bound enzymes generally stand better against thermal inactivation. To demonstrate this point, the sensor

performance and stability of native LDH were also examined. Paper sensors were prepared with native LDH following the same procedure as mentioned for CBD-LDH. Results showed the paper sensor quickly lost the majority of its functionality within 3 days of storage at $4^{\circ} \mathrm{C}$ or room temperature, or within 4 hours at $50^{\circ} \mathrm{C}$ (Fig. $8 \mathrm{C}$ ). The native enzyme (paper adsorbed) also showed a half lifetime of less than 20 hours (Fig. 8D). Apparently, the introduction of CBD stabilized the enzyme by a factor more than 25 -fold based on the half lifetime of enzyme.

\section{Conclusions}

We demonstrated in this work a novel colorimetric paper-based lactate sensor using a cellulose-binding recombinant enzyme. It has been shown that CBD-LDH can be immobilized on filter paper by the CBD tag with highly specific binding affinity. The CBD binding enhanced enzyme binding capacity and stability, leading to much improved sensor sensitivity and lifetime. The one-step binding procedure using enzyme crude extract promises an efficient sensor fabrication strategy for production of high performance paper sensors.

\section{Acknowledgement}


Dai thanks Chinese Scholarship Council for the support of an international scholarship for visiting research at UMN, and support from National Natural Science Foundation of China (21303050 and 31471659). Wang thanks partial support from Industrial Partnership for Research in Interfacial and Materials Engineering (IPRIME) of University of Minnesota. 


\section{Reference:}

[1] J. Yang, Y.G. Nam, S.K. Lee, C.S. Kim, Y.M. Koo, W.J. Chang, S. Gunasekaran, Paper-fluidic electrochemical biosensing platform with enzyme paper and enzymeless electrodes, Sens. Actuators B: Chem. 203 (2014) 44-53.

[2] L. Zhang, X. Cao, L. Wang, X. Zhao, S. Zhang, P. Wang, Printed microwells with highly stable thinfilm enzyme coatings for point-of-care multiplex bioassay of blood samples, Analyst 140 (2015) 4105-4113.

[3] S.M.Z. Hossain, R.E. Luckham, M.J. McFadden, J.D. Brennan, Reagentless bidirectional lateral flow bioactive paper sensors for tetection of pesticides in beverage and food samples, Anal. Chem. 81. 21 (2009) 9055-9064.

[4] L.B. Wang, W. Chen, D.H. Xu, B.S. Shim, Y.Y. Zhu, F.X. Sun, L.Q. Liu, C.F. Peng, Z.Y. Jin, C.L. Xu, N.A. Kotov, Simple, rapid, sensitive, and versatile SWNT-paper sensor for environmental toxin detection competitive with ELISA. Nano Lett. 9 (2009) 4147-4152.

[5] A. Martínez-Olmos, J. Ballesta-Claver, A. Palma, M.d.C. Valencia-Mirón, L. Capitán-Vallvey, A portable luminometer with a disposable electrochemiluminescent biosensor for lactate eetermination, Sensors 9 (2009) 7694.

[6] J.I. Hong, B.Y. Chang, Development of the smartphone-based colorimetry for multi-analyte sensing arrays, Lab Chip 14. 10 (2014) 1725-1732.

[7] N. Ratnarathorn, O. Chailapakul, C.S. Henry, W. Dungchai, Simple silver nanoparticle colorimetric sensing for copper by paper-based devices, Talanta 99 (2012) 552-557.

[8] A.C. Marques, L. Santos, M.N. Costa, J.M. Dantas, P. Duarte, A. Gonçalves, R. Martins, C.A. Salgueiro, E. Fortunato, Office paper platform for bioelectrochromic detection of electrochemically active bacteria using tungsten trioxide nanoprobes, Sci. Rep. UK. 5 (2015) 9910.

[9] A.W. Martinez, S.T. Phillips, E. Carrilho, S.W. Thomas III, H. Sindi, G.M. Whitesides, Simple telemedicine for developing regions: camera phones and paper-based microfluidic devices for realtime, off-site diagnosis, Anal. Chem. 80.10 (2008) 3699-3707.

[10] M. Arciuli, G. Palazzo, A. Gallone, A. Mallardi, Bioactive paper platform for colorimetric phenols 
detection, Sens. Actuators B: Chem. 186 (2013) 557-562.

[11] H.E. Klei, D.W. Sundstrom, D. Shim, In cells and enzymes—a practical approach; Woodward, J., Ed.; Oxford University Press: Oxford, 1985, p49.

[12] M. Zhou, M. Yang, F. Zhou, Paper based colorimetric biosensing platform utilizing cross-linked siloxane as probe, Biosens. Bioelectron. 55 (2014) 39-43.

[13] L. Kouisni, D. Rochefort, Confocal microscopy study of polymer microcapsules for enzyme immobilisation in paper substrates, J. Appl. Polym. Sci. 111.1 (2009) 1-10.

[14] M.P. Guerrero, F. Bertrand, D. Rochefort, Activity, stability and inhibition of a bioactive paper prepared by large-scale coating of laccase microcapsules, Chem. Eng. Sci. 66.21 (2011) 5313-5320.

[15] O. Shoseyov, Z. Shani, I. Levy, Carbohydrate binding modules: biochemical properties and novel applications, Microbiol. Mol. Biol. Rev. 70.2 (2006) 283-295.

[16] S. Hwang, J. Ahn, S. Lee, T. Lee, S. Haam, K. Lee, I.S. Ahn, J.K. Jung, Evaluation of cellulosebinding domain fused to a lipase for the lipase immobilization, Biotechnol. Lett. 26.7 (2004) 603-605.

[17] I. Levy, G. Ward, Y. Hadar, O. Shoseyov, C.G. Dosoretz, Oxidation of 4-bromophenol by the recombinant fused protein cellulose-binding domain-horseradish peroxidase immobilized on cellulose, Biotechnol. Bioeng. 82. 2 (2003) 223-231.

[18] W. Wan, D. Wang, X. Gao, J. Hong, Expression of family 3 cellulose-binding module (CBM3) as an affinity tag for recombinant proteins in yeast, Appl. Microbiol. Biotechnol. 91.3 (2011) 789-798.

[19] R. Hensel, U. Mayr, K.O. Stetter, O. Kandler, Comparative studies of lactic acid dehydrogenases in lactic acid bacteria, Arch. Microbiol. 112. 1 (1977) 81-93.

[20] P.R. Contag, M.G. Williams, P. Rogers, Cloning of lactate dehydrogenase from Clostridium acetobutylicum B463 and expression in Escherichia coli, Appl. Environ. Microbiol. 56 (1990) 37603765.

[21] L. Rassaei, W. Olthuis, S. Tsujimura, E.R. Sudhölter, A. Van den Berg, Lactate biosensors: current status and outlook, Anal. Bioanal. Chem. 406 (2014) 123-137.

[22] W. Dungchai, O. Chailapakul, C.S. Henry, Use of multiple colorimetric indicators for paper-based microfluidic devices, Anal. Chim. Acta 674 (2010) 227-233.

[23] J.S. Huston, D. Levinson, M. Mudgett-Hunter, M.S. Tai, J. Novotný, M.N. Margolies, R.J. Ridge, 
R.E. Bruccoleri, E. Haber, R. Crea, Protein engineering of antibody binding sites: Recovery of specific activity in an anti-digoxin single-chain Fv analogue produced in Escherichia coli, Proc. Natl. Acad. Sci. USA. 85. 16 (1988) 5879-5883.

[24] X. Chen, Y. Wang, P. Wang, Peptide-induced affinity binding of carbonic anhydrase to carbon nanotubes, Langmuir 31.1 (2015) 397-403.

[25] J. Hong, X. Ye, Y.H.P. Zhang, Quantitative determination of cellulose accessibility to cellulase based on adsorption of a nonhydrolytic fusion protein containing CBM and GFP with its applications, Langmuir 23. 25 (2007) 12535-12540.

[26] R. Cha, D. Wang, Z. He, Y. Ni, Development of cellulose paper testing strips for quick measurement of glucose using chromogen agent, Carbohyd. Polym. 88.4 (2012) 1414-1419.

[27] M. Akram, R. Daly, F. da Cruz Vasconcellos, A.K. Yetisen, I. Hutchings, E.H. Hall, Applications of paper-based diagnostics, in: J. Castillo-León, W.E. Svendsen (Eds.) Lab-on-a-Chip Devices and Micro-Total Analysis Systems, Springer International Publishing, 2015, pp. 161-195.

[28] M.V. Berridge, P.M. Herst, A.S. Tan, Tetrazolium dyes as tools in cell biology: new insights into their cellular reduction, Biotechnol. Annu. Rev. 11 (2005) 127-152.

[29] A.W. Martinez, S.T. Phillips, M.J. Butte, G.M. Whitesides, Patterned paper as a platform for inexpensive, low volume, portable bioassays, Angew. Chem. Int. Ed. 46.8 (2007) 1318-1320.

[30] E.I. Garvie, Bacterial lactate dehydrogenases, Microbiol. Rev. 44.1 (1980) 106-139.

[31] B. Phypers, J.M.T. Pierce, Lactate physiology in health and disease, Continuing Education in Anaesthesia, Crit. Care Pain. 6.3 (2006) 128-132.

[32] W.C. Stanley, E.W. Gertz, J.A. Wisneski, D.L. Morris, R.A. Neese, G.A. Brooks, Systemic lactate kinetics during graded exercise in man, Am. J. Physiol. Endocrinol. Metab. 249. 6 (1985) E595-E602.

[33] N. Thomas, I. Lähdesmäki, B.A. Parviz, A contact lens with an integrated lactate sensor, Sens. Actuators B: Chem. 162 (2012) 128-134.

[34] A.C. Pereira, M.R. Aguiar, A. Kisner, D.V. Macedo, L.T. Kubota, Amperometric biosensor for lactate based on lactate dehydrogenase and Meldola Blue coimmobilized on multi-wall carbon-nanotube, Sens. Actuators B: Chem. 124 (2007) 269-276.

[35] M.R. Romero, F. Garay, A.M. Baruzzi, Design and optimization of a lactate amperometric biosensor 
based on lactate oxidase cross-linked with polymeric matrixes, Sens. Actuators B: Chem. 131 (2008) $590-595$.

[36] A. Chaubey, K.K. Pande, V.S. Singh, B.D. Malhotra, Co-immobilization of lactate oxidase and lactate dehydrogenase on conducting polyaniline films, Anal. Chim. Acta 407.1 (2000) 97-103.

[37] A. Chaubey, M. Gerard, R. Singhal, V.S. Singh, B.D. Malhotra, Immobilization of lactate dehydrogenase on electrochemically prepared polypyrrole-polyvinylsulphonate composite films for application to lactate biosensors, Electrochim. Acta 46 (2001) 723-729.

[38] G.L. Gordon, H.W. Doelle, Purification, properties and immunological relationship of L(+)-Lactate Dehydrogenase from Lactobacillus casei, Eur. J. Biochem. 67.2 (1976) 543-555. 
Table1.

Primers designed and applied in the current work

\begin{tabular}{clc}
\hline Primer & Sequence $\left(5^{\prime} \rightarrow 3^{\prime}\right)$ & Underlined \\
\hline LDH-F & GGAATTCCATATGGCAAGTATTACGGATAA & Nde I \\
LDH-linker-r & AGAACCACCACCTCCAGATCCTCCTCCACCAGAACCTCCACCTCCCTGACGGGTT & $\left(\mathrm{G}_{4} \mathrm{~S}\right)_{3}$ \\
Linker-CBD-f & GGAGGTGGAGGTTCTGGTGGAGGAGGATCTGGAGGTGGTGGTTCTCCGGTATCAG & $\left(\mathrm{G}_{4} \mathrm{~S}\right)_{3}$ \\
CBD-R & CCGCTCGAGTTAGGGTTCTTTACCCCATACAAGAACACCG & Xho I \\
\hline
\end{tabular}


Table 2

Maximum binding capacities of recombinant LDH

\begin{tabular}{ccc}
\hline Enzymes & $\begin{array}{c}\text { Binding } \\
\text { Capacity }(\mathrm{mg} / \mathrm{g})\end{array}$ & $\begin{array}{c}\text { Binding Capacity } \\
(\mu \mathrm{mol} / \mathrm{g})\end{array}$ \\
\hline LDH & $0.23 \pm 0.03$ & $0.006 \pm 0.001$ \\
Purified CBD-LDH & $21.7 \pm 0.25$ & $0.402 \pm 0.005$ \\
CBD-EGFP & $20.2 \pm 1.07$ & $0.452 \pm 0.024$ \\
Unpurified CBD-LDH & $9.04 \pm 0.09$ & $0.167 \pm 0.002$ \\
\hline
\end{tabular}




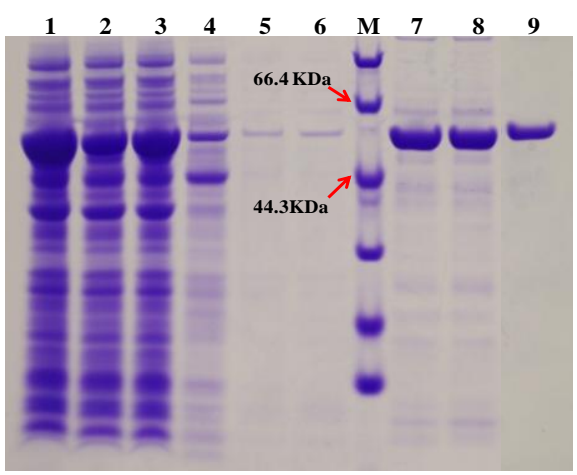

Fig. 1. SDS-PAGEA analysis of CBD-LDH. (Lane 1: crude lysate; Lanes 2\&3: flow-through fraction samples with fresh buffer; Lane 4: the flow-through fraction washed with the $20 \mathrm{mM}$ imidazole buffer; Lanes 5\&6: flow-through fraction samples washed with the $40 \mathrm{mM}$ imidazole buffer; M: molecular mass marker; Lanes 7\&8: recombinant CBD-LDH purified from E. coli strain BL-21 (DE3) eluted by the $80 \mathrm{mM}$ imidazole buffer; Lane 9: recombinant CBD-LDH purified with the $200 \mathrm{mM}$ imidazole buffer). 


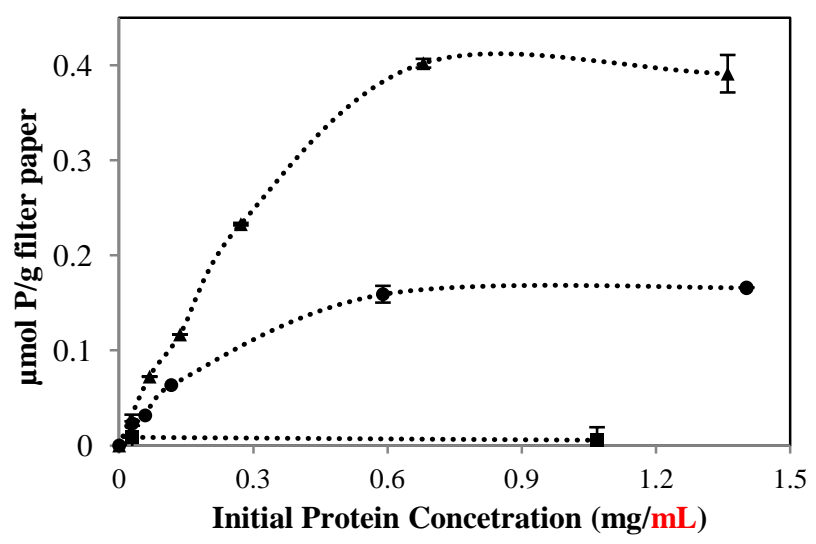

Fig. 2. Adsorption of $\mathrm{LDH}$ on filter paper. (Tested with $50 \mathrm{mM}$ Tris- $\mathrm{HCl} \mathrm{pH} 8.5$ buffer at $30^{\circ} \mathrm{C}$; $\boldsymbol{\Delta}$ : Purified CBD-LDH; : Crude CBD-LDH; $\mathbf{\square}$ : Native LDH). 


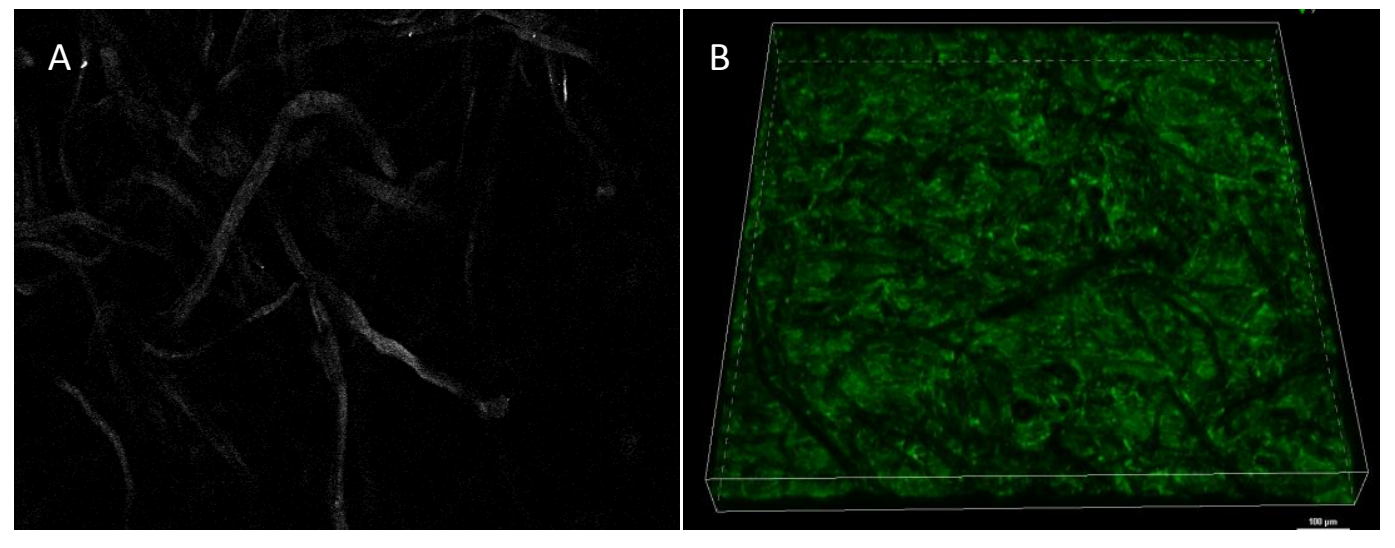

Fig. 3. Laser scanning confocal microscopy images of protein distribution on filter paper. The excitation/emission wavelengths were 488 and $507 \mathrm{~nm}$, respectively, with a scanning resolution as 414.32 nm/px. ((A): blank cellulose paper, shows essentially no green fluorescence; (B): filter paper bond with CBD-EGFP.) 


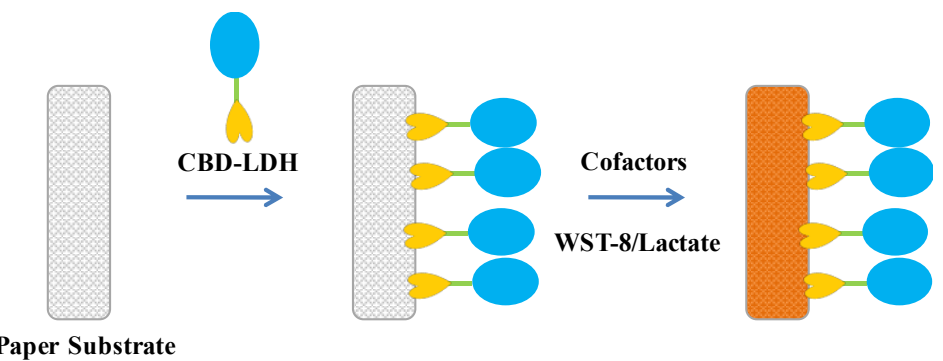

Fig. 4. Scheme of preparation of paper sensor with crude CBD-LDH. 


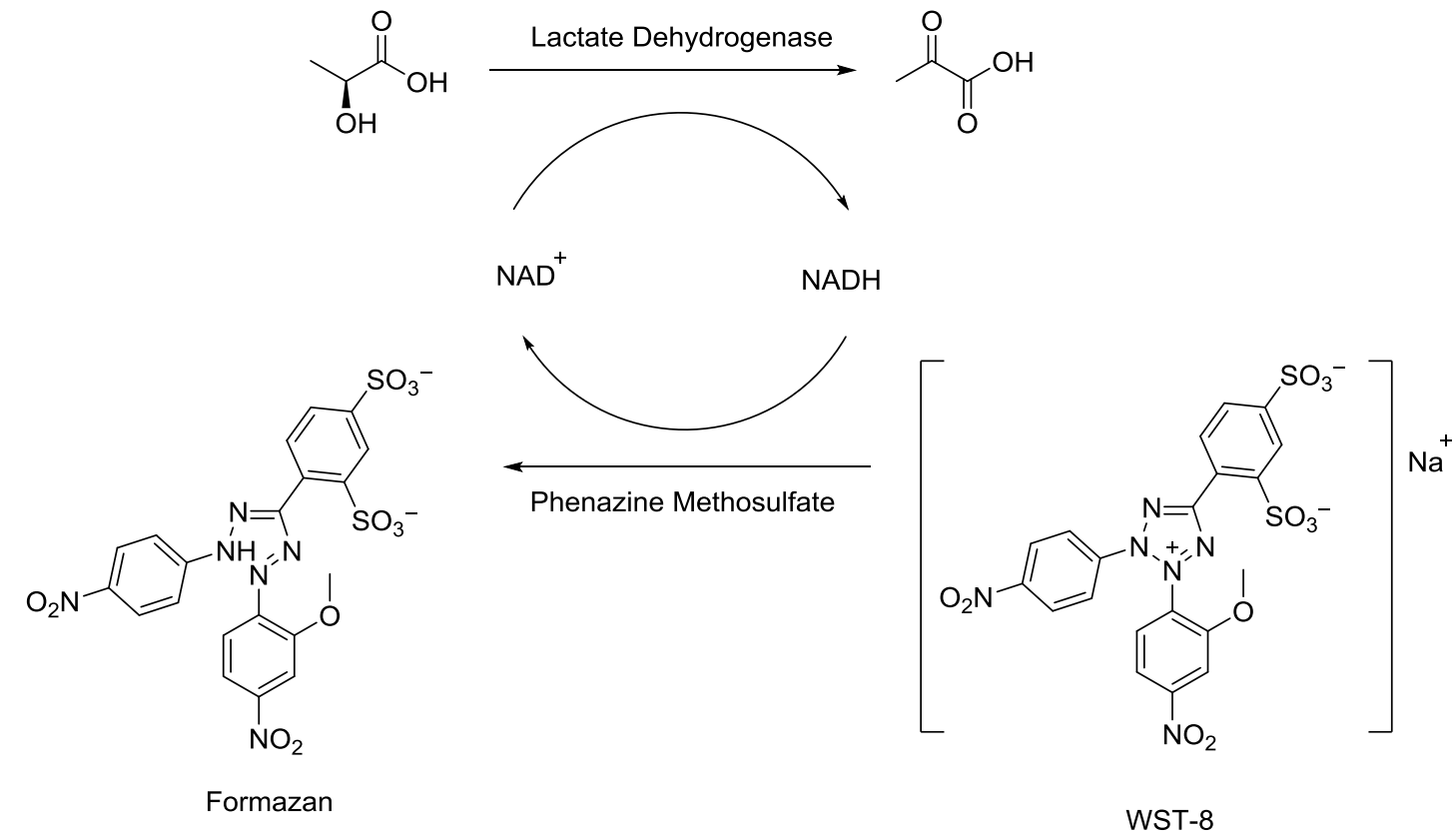

Fig. 5. Reaction scheme for the detection of lactate using LDH applied for the paper sensor. (NADH generated from the LDH-catalyzed oxidation reaction of lactate is oxidized to $\mathrm{NAD}^{+}$catalyzed by PMS in the presence of WST-8. WST-8 is reduced and yields an orange color.) 


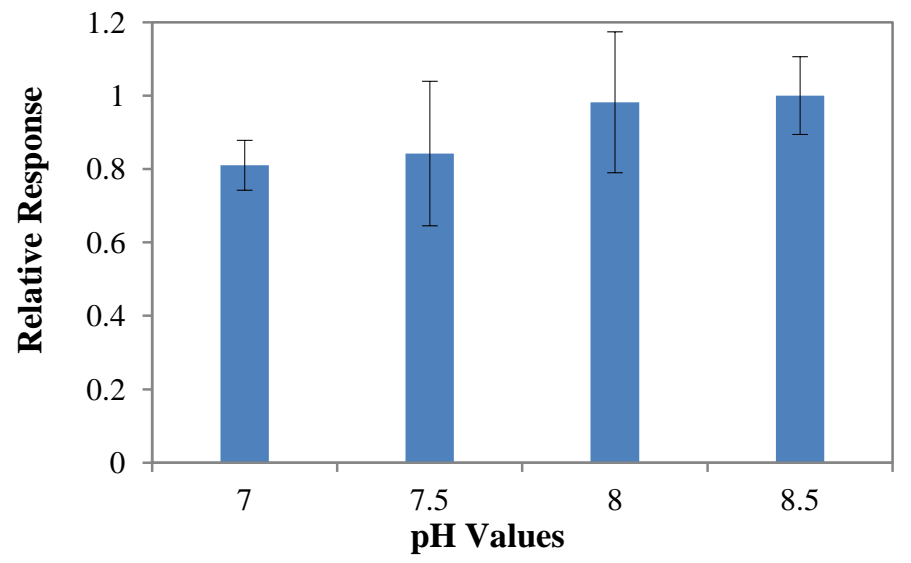

Fig. 6. Effect of $\mathrm{pH}$ on sensitivity of paper sensor. (Tested with a sample solution of $3 \mathrm{mM}$ of lactate at different $\mathrm{pH}$ in $50 \mathrm{mM}$ Tris-HCl. The relative response was calculated by normalizing the color density to the average reading at $\mathrm{pH} 8.5$.) 
A

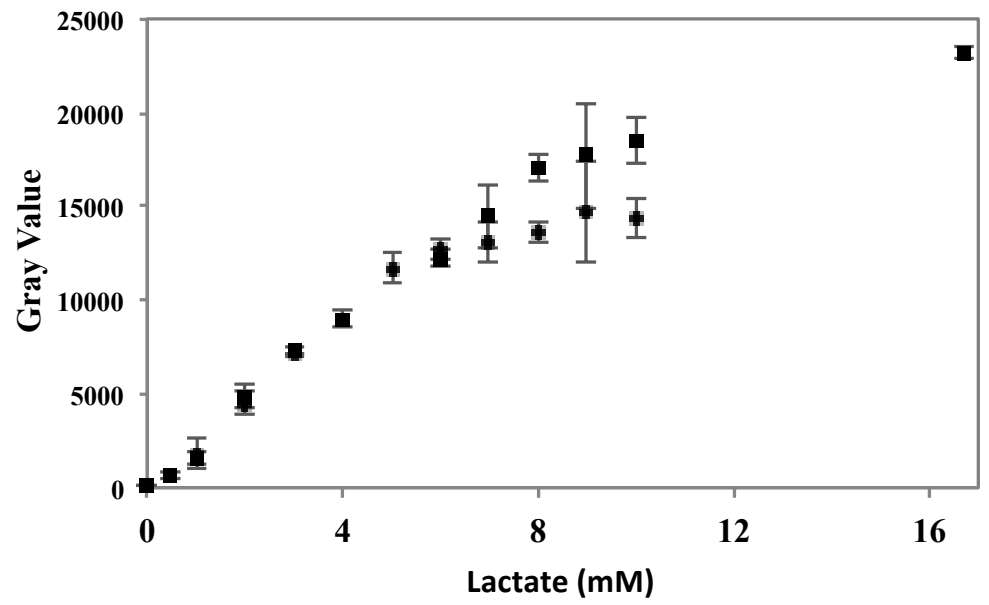

B

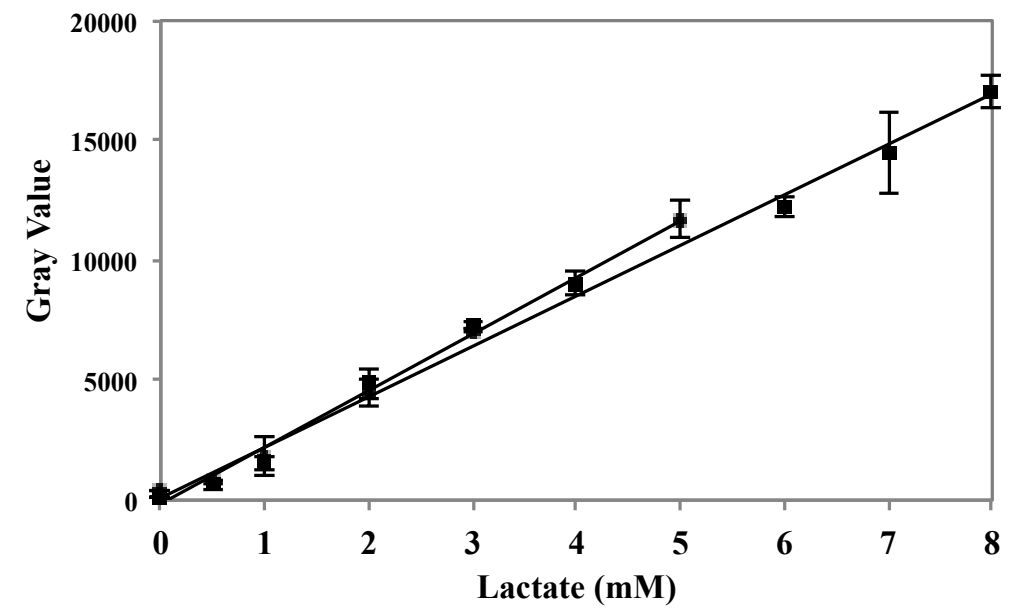

C

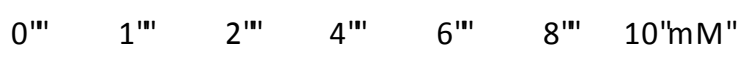

Fig. 7. Calibration curves of lactate using CBD-LDH paper sensor. ((A) Calibration curves; (B) Linear range of the calibration curves; (C) photo images of color development of the paper sensor. Experimental data in $(\mathrm{A})$ and $(\mathrm{B})$ : - assay reaction set for $30 \mathrm{~min}$; - assay reaction set for $15 \mathrm{~min}$. The solid lines in (B) represent a linear regression fit of the experimental data.) 

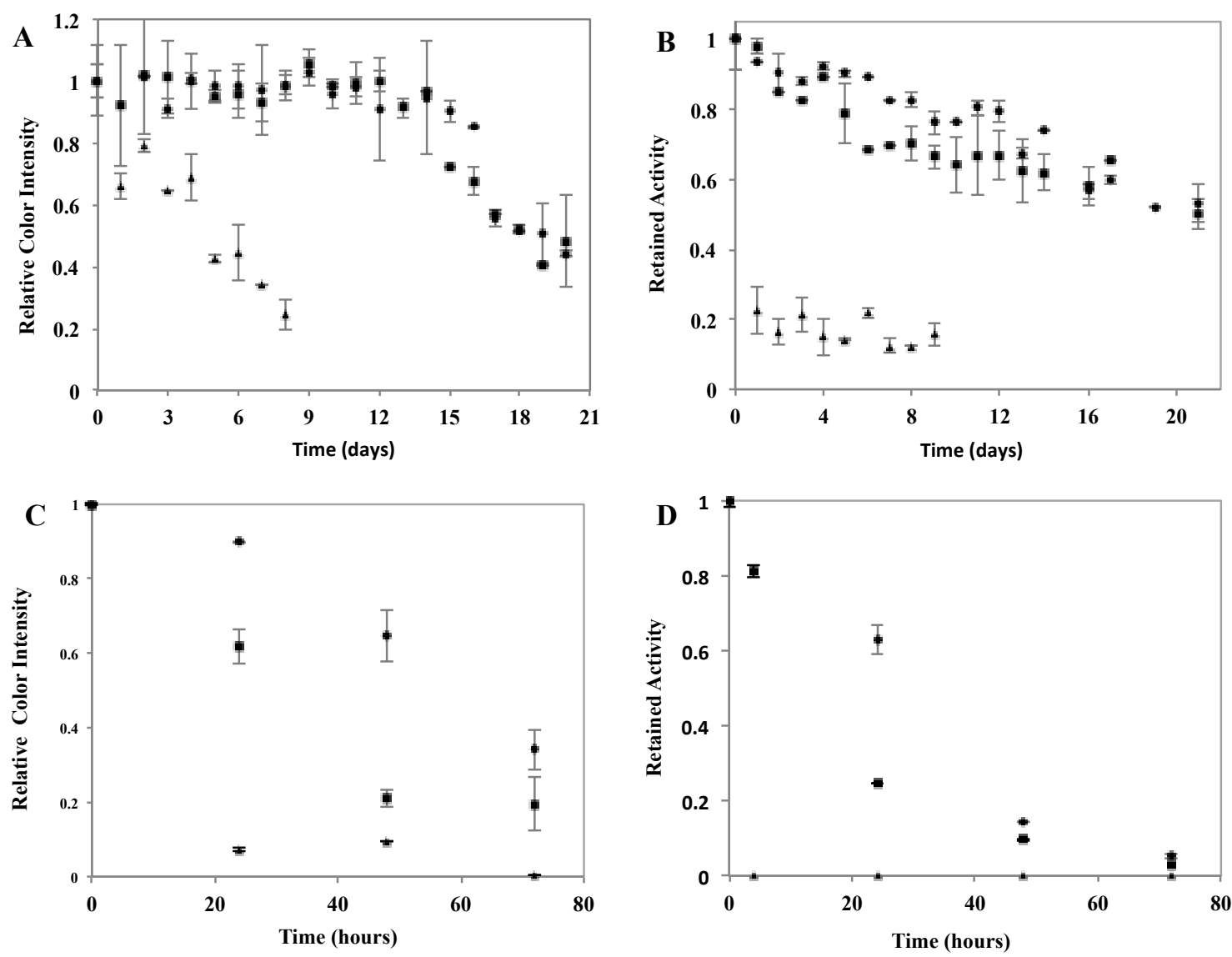

Fig. 8. Stability of CBD-LDH paper sensor. ((A) Relative sensor sensitivity of CBD-LDH-based paper sensor; (B) Relative enzyme activity of paper-bound CBD-LDH; (C) Relative sensor sensitivity of native LDH-based paper sensor; (D) Relative enzyme activity of paper-bound native LDH. Experimental data: - stability at $4{ }^{\circ} \mathrm{C} ; \boldsymbol{-}$ - stability at room temperature; $\boldsymbol{\Delta}$ - stability at $50^{\circ} \mathrm{C}$ ). 